\title{
Introduction to HICCS-50 Minitrack on Digital and Social Media in Enterprise
}

\author{
Xuefei (Nancy) Deng \\ California State University, \\ Dominguez Hills, ndeng@csudh.edu
}

\author{
Yibai Li \\ University of Scranton \\ yibai.li@scranton.edu
}

\author{
K. D. Joshi \\ Washington State University \\ joshi@wsu.edu
}

Digital and social media (DSM) have transformed the workplace in organizations. Two decades ago, the use of electronic communication technologies--such as emails, messaging, and teleconference systems-promoted effective electronic communications in organizations, changing organizational forms, enabling electronic document management, and preserving organizational memory. Now organizations are experiencing an exponential growth in the use of a new wave of digital media, social media technologies such as blogs, wikis, social networking sites, and microblogging that provide new affordances. While scholars have examined the use of social media technologies for organizational external communications (e.g., with customers and vendors), our understanding of the digital and social use within organizations remains limited. In order for an organization to amplify the returns/benefits and to mitigate the drawbacks of DSM use within the work environment, it is imperative for both researchers and practitioners to focus on the implications of digital and social media use for organizational actions.

This minitrack presents theoretical and empirical studies addressing organizational, managerial, technical, and behavioral perspectives on digital and social media in enterprises. Issues and topics of study include new organizational work issues associated with digital and social media use, information security and the use/misuse of digital and social media at workplace, and effects of and support for digital and social media in enterprise. This research lies at the intersectionality of multiple disciplines, namely Information Systems, Science \& Technology, Organization Science, and Behavioral Science.

This year the minitrack presents four papers on topics ranging from enterprise digital and social media challenges and impacts to communication platforms and strategic implications. We introduce the four papers briefly below.

The first paper is entitled "Spanning the Boundary: Measuring the Realized and Lifecycle Impact of Distinct Boundary Spanning Activities on Project Success and Completion.” Drawing on log and content data from 169 projects in an enterprise social media of a large multi-national corporation, Wietske Van Osch, Charles Steinfield, and Yanjie Zhao assessed the effect of boundary spanning on project success and provided a qualitative path model of the evolution of boundary-spanning activities throughout the lifecycle of a project through a comparison of successful versus unsuccessful projects.

In the second paper, entitled "Moderation of Enterprise Social Networks - A Literature Review from a Corporate Perspective," Ferry Nolte, Nadine Guhr, and Michael H. Breitner conduct a structured literature review to identify pre-existing IS contributions to the moderation phenomenon in social media tools, explaining how to moderate these communication platforms in the enterprise context. Their assessment of three different moderation approaches is based on the review of over 150 articles on the subject of corporate engagement and user content.

In the context of higher education institutions, Delphine Colin and Sarah Mahr examine students' perceptions of universities' digital advancement in their paper entitled "Exploring the Impact of Universities' Digital Advancement on Students' Perceptions - A Driver of Reputation and WOM behavior?" Their paper introduces a measurement for students' perception of their universities' digital advancement (PDA). Results of a PLS-SEM model show that the PDA construct is an influential driver for universities' likeability and students' related word of mouth (WoM) behavior.

Finally, with the increasing use of social media by entrepreneurs, it becomes important to for academia and practitioners alike to understand how entrepreneurs use the platform to develop meaningful connections with their stakeholders and customers. That research objective is achieved by Fang (Florence) Wang (Wong), Jason Kuruzovich, and Yingda $\mathrm{Lu}$ in their study entitled "Entrepreneurs' Activities on Social Media and Venture Financing." Their empirical analysis demonstrates how differences in entrepreneurs' tweets are associated with different 
levels of startup engagement and venture financing. The data analysis of over 7,000,000 tweets from entrepreneurs and startups indicates association between the social media activities of entrepreneurs, startup engagement, and venture financing.

As the nature and roles of digital and social media in enterprise will continue to evolve, so will the scope of our minitrack. Created in 2014 as HICCS-47 Minitrack on Social Media and Workplace: Job and Work Design Issues in a Social Enterprise, this minitrack has grown and expanded its scope from organizational challenges and work/job design issues arising from enterprise social media to including organizational, managerial, technical, and behavioral perspectives on enterprise digital social media. Looking forward beyond HICSS-50, this minitrack hope to contribute the DSM field by continuing to attract and present latest digital and social media research in the enterprise setting. 